\title{
3' Untranslated Region SNP
}

National Cancer Institute

\section{Source}

National Cancer Institute. 3' Untranslated Region SNP. NCI Thesaurus. Code C45394.

A 3' Untranslated Region SNP consists of a variation at an appreciable frequency

between individuals of a single interbreeding population of a single nucleotide, due to base substitution, at an equivalent location within the sequence region at the 3 ' end of a messenger RNA (following the stop codon) that is not translated into protein and may contain transcription and translation regulating sequences. 